Sharif University of Technology
Scientia Iranica
Transactions E: Industrial Engineering
http://scientiairanica.sharif.edu
IRAN ICA

\title{
Sustainable procurement decision of electric coal under fuzzy information environment
}

\author{
C. Rao ${ }^{\mathrm{a}}, \mathrm{C} \cdot \mathrm{Wang}^{\mathrm{b}, *}, \mathrm{Z} \cdot \mathrm{Hu}^{\mathrm{c}}, \mathrm{Y} \cdot \mathrm{Meng}^{\mathrm{a}}$, and M. Liu ${ }^{\mathrm{a}}$ \\ a. School of Science, Wuhan University of Technology, Wuhan 430070, P.R. China. \\ b. School of Mathematics and Economics, Hubei University of Education, P.R. China. \\ c. College of Automation, Wuhan University of Technology, Wuhan 430070, P.R. China.
}

Received 21 August 2017; received in revised form 7 December 2017; accepted 17 February 2018

\author{
KEYWORDS \\ Electric coal; \\ Multi-attribute \\ and multi-source \\ procurement; \\ Supplier selection; \\ Linguistic fuzzy \\ variable; \\ 2-tuple; \\ 2-tuple deviation \\ degree.
}

\begin{abstract}
Green supply chain management is a crucial challenge for the sustainable development of enterprises. This study investigates the problem of supplier selection for the multi-attribute and multi-source green procurement of electric coal under fuzzy information environment. Concretely, a new index system of supplier selection is established by considering both the economic and environmental factors; then, a multi-attribute decisionmaking method based on 2-tuple deviation degree is presented to rank all alternative suppliers in the green procurement of electric coal. The implementation, availability, and feasibility of the green procurement decision method of electric coal are also highlighted by using an example of the multi-source procurement of electricity coal. An attempt is made to provide a theoretical basis and decision-making reference for the thermal power enterprise to implement scientific green procurement management of electric coal.
\end{abstract}

(C) 2019 Sharif University of Technology. All rights reserved.

\section{Introduction}

Electric coal is one of the main raw materials for the thermal power generation, that is, it is a kind of coal used to generate electricity. The electric coal procurement is the basis of safe and stable generation of thermal power [1-3]. In the practical procurement of electric coal, the task of the procurement managers in thermal power enterprise is to evaluate and select the right and optimal suppliers using smart and effective procurement strategies to help enterprises enhance comprehensive competitiveness and maintain a strategically competitive position [4-7].

Many scholars studied the supplier selection problem of electric coal procurement. For example, Shiromaru et al. [8] used fuzzy satisfaction methods to deal

\footnotetext{
*. Corresponding author.

E-mail address: wangc80@163.com (C. Wang)
}

with the fuzzy information in the process of electric coal procurement and used the genetic algorithm to select the supplier; Lai and Yang [9] presented a multilayer optimization procurement model to evaluate and select the optimal suppliers for the power-generation enterprises; Dai et al. [10] proposed a supplier selection model based on a quantity discount contract; Yan [11] established an experimental platform of E-commerce coordinate system for selecting electric coal suppliers, etc. Based on the existing literatures on the practical electric coal procurement, the buyer considers multiple aspects when evaluating and selecting the optimal supplier, e.g., the coal mine production, the railway transportation, the highway transportation, the waterway transportation, and so on. Most of the existing methods for optimal supplier selection in electric coal procurement have only considered economic criteria, such as quality, price, delivery time, flexibility, etc., when evaluating supplier performance. Their main goal is to maximize the benefits of enterprises. However, with the development of society, the environmental problem is 
getting increasingly serious. A large quantity of waste gas, wastewater, and waste solid material was produced during the production of electric coal. Therefore, it very seriously polluted the environment [12-14]. In this sense, the buyer in a sustainable thermal power enterprise must also consider the environmental factors, in addition to the economic factors, when evaluating supplier performance in supplier selection.

In addition, the attribute values under these economic and environmental dimensions may be multiple data types, e.g., the attribute values of price, quantity, and delivery time are generally evaluated in the form of real numbers. However, due to the complexity of the decision-making environment and the ambiguity of the human mind, many attributes are difficult to quantify as an accurate real number, e.g., the supplier's reputation, supplier service level, and some environmental attributes (atmospheric pollution degree, environmental management level, etc.); thus, the values of these attributes are usually given in the form of linguistic fuzzy variables such as best, good, acceptable, poor, worst, etc. [15-31]. Thus, the decisionmaking on the supplier selection of electric coal procurement belongs to a kind of multi-attribute decision making under fuzzy information environment [32-46]. Further, because the supply of a single supplier in quantity and variety is limited, it is often difficult to meet the needs of the buyer within the given time. The buyer can select multiple suppliers to supply electric coal at the same time. Therefore, an optimal method is presented to solve this problem of multi-attribute and multi-source decision-making about the supplier selection of electric coal procurement.

Based on the above analysis, we focus on the following research questions in this paper:

(1) Construct the evaluation system for supplier selection by considering both the economic and environmental factors from a perspective of green supply chain management;

(b) Design an optimal decision-making method for supplier selection of electric coal based on a 2-tuple deviation degree. An attempt is made to provide a theoretical basis and decision-making reference for the thermal power enterprise to implement scientific green procurement management of electric coal under the fuzzy information environment.

Compared with the existing methods for procurement decision of electric coal, in our decision method, the supplier selection problem in the multi-source and multi-attribute green procurement of electric coal is transformed into hybrid multi-attribute decision-making problems with hybrid attribute data (the real numbers and linguistic fuzzy variables coexist). In the decision process, all hybrid data of alternative suppliers are transformed into the linguistic 2-tuples [25-28,33,47-49], and a new ranking method-2-tuple deviation degree is presented to rank all alternative suppliers and select winners. This data process can effectively prevent the loss and distortion of information in the process of information collection compared with some traditional methods. However, there are not many methods among the traditional MADM methods to deal with this kind of hybrid multi-attribute decision-making problems with hybrid attribute data. Even though there are a few, most of them transform the hybrid data into a single type data (real numbers, or interval number, or triangle fuzzy numbers); then, a comprehensive evaluation is made. This data process method is easy to cause information loss and information distortion.

The rest of this paper is organized as follows. Section 2 constructs the evaluation system for supplier selection from economic and environmental dimensions. Section 3 presents an optimal decisionmaking method for electric coal supplier selection based on 2-tuple deviation degree. Section 4 gives an example of the multi-source procurement of electricity coal to highlight the implementation, availability, and feasibility of the green procurement decision method. Section 5 concludes the paper.

\section{The evaluation index system of selecting electric coal suppliers}

In this section, a new evaluation system for supplier selection of electric coal is established. As environmental protection is critical to good green supply chain management, supplier selection requires considering the environmental and economic factors. In this paper, based on the existing related research [2,3,6-10,12$13]$, both the economic and environmental factors are considered as follows:

\section{Attributes under the economic dimension:}

$A_{1}$ price represents the purchase price per ton of electric coal for a buyer (in Yuan/ton). The value of price will be directly submitted to the buyer in the form of a real number by the electric coal suppliers.

$A_{2}$ quantity is the largest amount of electric coal that a supplier can supply for a fee at a certain time (in ton). Usually, the value of quantity will be directly submitted to the buyer in the form of a real number by the suppliers in conjunction with their production capacity and actual production.

$A_{3}$ delivery time is the time taken by a supplier to deliver the electric coal to a buyer under contract (in day). Delivery time reflects the transport capacity of suppliers, and short delivery time represents high transportation ability. The value of delivery time will be directly submitted 
to the buyer in the form of a real number by the electric coal suppliers.

$A_{4}$ quality is a core attribute in electric coal supplier evaluation. The quality level of electric coal can be characterized by the implementation level of relative quality standard system. Usually, the common quality standard is the electric coal national standard GB/T7562-2010 [50]. In this standard, some quality attributes must satisfy the basic standard; for example, the calorific value (in $\mathrm{MJ} / \mathrm{kg}$ ) must be greater than 12 and is generally divided into five grades: $>24,21.01 \sim 24,17.01 \sim 21$, $15.51 \sim 17,>12$; the volatile matter (in percentage) must be greater than 6.5 and is generally divided into five grades: $6.5 \sim 10,10.01 \sim 20,20.01 \sim 28$, $>28$, and $>37$; the ash melting point (in ${ }^{\circ} \mathrm{C}$ ) must be greater than 1150 and is generally divided into four grades: $>1150 \sim 1250,1260 \sim 1350,1360 \sim 1450$, $>1450$; the ash (in \%) must be less than 40, and the ash is generally divided into three grades: $\leq 20$, $20 \sim 30,30 \sim 40$; the moisture (in \%) must be greater than 8 and is generally divided into four grades: $\leq 8,8.1 \sim 12,12.1 \sim 20,>20$; the sulfur coal classification (in \%) cannot be more than $2.5 \%$ and is generally divided into four grades: $\leq 0.5,0.51 \sim 1$, $1.01 \sim 2,2.01 \sim 3$.

$A_{5}$ Supplier's reputation is the reputation degree, determining whether the suppliers can strictly fulfill the requirements of the procurement contract to provide high-quality electric coal for buyers within the specified time.

The attribute values of quality level of electric coal and supplier's reputation are usually given in the form of linguistic fuzzy variables, such as best, good, acceptable, poor, and worst, evaluated by the buyer.

2. Attributes under the environmental dimension:

$A_{6}$ carbon dioxide emission level. Its purpose is to protect the environment and slow global warming by cutting carbon dioxide emissions. The lower the level of carbon dioxide emission, the better the supplier.

$A_{7}$ wastewater discharge level refers to the density level of the indices such as physical water pollution, chemical water pollution, and biological water pollution.

$A_{8}$ Solid waste generation level mainly refers to the control degree of the remaining sludge and industrial waste from metal processing, smelting, casting, power production of raw materials, and water treatment.

The reduction rate of wastewater, waste gas, and solid waste reflects the degree of waste reduction. Ecotype enterprises slash the emission of waste water, waste gas, and solid waste in the process of construction. The recommended values are as follows. The reduction rate of wastewater emission should be greater than $40 \%$, the reduction rate of waste gas emission should be greater than $20 \%$, and the reduction rate of solid waste emission should be greater than $30 \%$.

$A_{9}$ recycling utilization rate of waste materials refers to the percentage of recycling utilization amount of waste material to the total generation amount of waste material. Generally, in order to realize the material integration, energy integration, and water resources integration, the recycling utilization rate of waste material should not be less than $80 \%$.

$A_{10}$ investment rate of environmental protection refers to the percentage of the total investment of environmental protection to the total investment of the enterprise within a certain period of time. Generally, the green supply chain requires that an enterprise's investment rate of environmental protection be more than $3.0 \%$.

$A_{11}$ Environmental management level is mainly measured by the development and implementation of environmental management systems and related regulations as well as the level of environmental information management.

The values of attributes $A_{6}, A_{7}, A_{8}, A_{9}$, $A_{10}$, and $A_{11}$ under the environmental dimension are usually given in the form of linguistic fuzzy variables, such as best, good, acceptable, poor, and worst, evaluated by the buyer.

For the above 11 attributes, the values of $A_{1}$ price and $A_{3}$ delivery time are given in the form of real numbers and are cost type attributes; the values of $A_{2}$ quantity are also given in the form of real numbers; however, $A_{2}$ is a benefit type attribute. The other 8 attributes are given in the form of linguistic fuzzy variables and are all transformed as benefit type attributes.

Now, it is supposed that a buyer in a powergeneration enterprise wants to procure $Q_{0}$ tons of electric coal. $m(m \geq 2)$ suppliers take part in the supply competition. The above 11 attributes are used to evaluate $m$ suppliers' performance. The values of these 11 attributes for $m$ suppliers form the original decision-making matrix:

$$
X=\left(x_{i j}\right)_{m \times 11}, \quad i=1,2, \cdots, m,
$$

where $x_{i j}$ is the attribute value of supplier $i$ under attribute $j, j=1,2, \cdots, 11$. In addition, we suppose that the weight set of above 11 attributes is $W=\left(w_{1}, w_{2}, \cdots, w_{11}\right)$, such that $0 \leq w_{j} \leq 1$ and $\sum_{j=1}^{11} w_{j}=1$. We can determine the values of attribute weights by the method of analytic hier- 
archy process or the Delphi method in the practical decision-making procurement of electricity coal.

\section{Supplier selection method based on 2-tuple deviation degree}

Based on the data information in the original decisionmaking matrix $X=\left(x_{i j}\right)_{m \times 11}$, our decision goal is to select the optimal suppliers to supply $Q_{0}$ units of electric coal to the buyer. Now, in this section, we will present an optimal decision-making method of electric coal supplier selection based on 2-tuple deviation degree.

\subsection{Preliminaries}

The 2-tuple [47-49] was first presented by professor Herrera of Spain in 2000; he used a dual combination $\left(s_{k}, a_{k}\right)$ to express the evaluation result of an evaluation objective, where $s_{k}$ is the $k$ th element in a predefined linguistic term set $S, S=\left\{s_{0}, s_{1}, \cdots, s_{h}\right\}$, where $s_{0}, s_{1}, \cdots, s_{h}$ are $h+1$ linguistic fuzzy variables. Also, $a_{k}$ is a numerical value that represents the value of the symbolic translation, such that $a_{k} \in[-0.5,0.5)$, implying the deviation between the evaluation result and $s_{k}$. The dual combination $\left(s_{k}, a_{k}\right)$ is called a 2 tuple.

For a predefined linguistic term set, $S=$ $\left\{s_{0}, s_{1}, \cdots, s_{h}\right\}$, the following properties are satisfied, i.e.:

(i) If $k \geq l$, then $s_{k} \geq s_{l}$;

(ii) There exists a negation operator $\operatorname{Neg}\left(s_{k}\right)=s_{l}$, where $l=h-k$;

(iii) If $s_{k} \geq s_{l}$, then $\max \left(s_{k}, s_{b}\right)_{k}$ and $\min \left(s_{k}, s_{l}\right)=s_{l}$.

Now, some definitions are presented $[47,48]$ on $2-$ tuple.

Definition 1. Let $s_{k} \in S$ be a linguistic fuzzy variable; then, the corresponding linguistic 2-tuple can be obtained by the following function, $\theta$ :

$$
\begin{aligned}
& \theta: S \rightarrow S \times[-0.5,0.5), \\
& \theta\left(s_{k}\right)=\left(s_{k}, 0\right), \quad s_{k} \in S .
\end{aligned}
$$

Definition 2. Let $S=\left\{s_{0}, s_{1}, \cdots, s_{h}\right\}$ be a linguistic term set and $\beta \in[0,1)$ be a value supporting the result of a symbolic aggregation operation. Then, the 2-tuple that expresses the equivalent information is obtained with the following function:

$$
\begin{aligned}
& \Delta:[0,1) \rightarrow S \times[-0.5,0.5), \\
& \Delta(\beta)=\left(s_{k}, a_{k}\right),
\end{aligned}
$$

where:

$$
\left\{\begin{array}{l}
k=\operatorname{round}(\beta \cdot t) \\
a_{k}=\beta \cdot t-k, \quad a_{k} \in[-0.5,0.5)
\end{array}\right.
$$

and "round" is the usual rounding operation. Conversely, if $\left(s_{k}, a_{k}\right)$ is a known 2-tuple, then there is an inverse function $\Delta^{-1}$ such that, from a 2-tuple $\left(s_{k}, a_{k}\right)$, it returns its equivalent numerical value, $\beta \in[0,1)$, i.e.:

$$
\begin{aligned}
& \Delta^{-1}: S \times[-0.5,0.5) \rightarrow[0,1), \\
& \Delta^{-1}\left(s_{k}, a_{k}\right)=\frac{k+a_{k}}{t}=\beta .
\end{aligned}
$$

Definition 3. Let $S=\left\{s_{0}, s_{1}, \cdots, s_{h}\right\}$ be a linguistic term set and $\beta \in[1, h]$ be a value supporting the result of a symbolic aggregation operation. Then, the 2-tuple that expresses the equivalent information is obtained with the following function:

$$
\begin{aligned}
& \Delta:[1, h] \rightarrow S \times[-0.5,0.5), \\
& \Delta(\beta)= \begin{cases}s_{k}, & k=\operatorname{round}(\beta) \\
a_{k}=\beta-k, & a_{k} \in[-0.5,0.5)\end{cases}
\end{aligned}
$$

where "round" is the usual rounding operation. Conversely, if $\left(s_{k}, a_{k}\right)$ is a known 2-tuple, then there is an inverse function $\Delta^{-1}$ such that, from a 2 -tuple $\left(s_{k}, a_{k}\right)$, it returns its equivalent numerical value $\beta \in[1, h]$, i.e.:

$$
\begin{aligned}
& \Delta^{-1}: S \times[-0.5,0.5) \rightarrow[1, h], \\
& \Delta^{-1}\left(s_{k}, a_{k}\right)=k+a_{k}=\beta .
\end{aligned}
$$

Definition 4. For any two linguistic 2-tuples $\left(s_{k}, a_{k}\right)$ and $\left(s_{l}, a_{l}\right)$, their compared operations are defined as follows:

1. If $k>l$, then $\left(s_{k}, a_{k}\right)>\left(s_{l}, a_{l}\right)$,

2. If $k=l$, then:

(i) $a_{k}=a_{l}$, then $\left(s_{k}, a_{k}\right)=\left(s_{l}, a_{l}\right)$;

(ii) $a_{k}>a_{l}$, then $\left(s_{k}, a_{k}\right)>\left(s_{l}, a_{l}\right)$;

(iii) $a_{k}<a_{l}$, then $\left(s_{k}, a_{k}\right)<\left(s_{l}, a_{l}\right)$.

3. If $\left(s_{k}, a_{k}\right) \geq\left(s_{l}, a_{l}\right)$, then:

$$
\begin{aligned}
& \max \left\{\left(s_{k}, a_{k}\right),\left(s_{l}, a_{l}\right)\right\}=\left(s_{k}, a_{k}\right), \\
& \min \left\{\left(s_{k}, a_{k}\right),\left(s_{l}, a_{l}\right)\right\}=\left(s_{l}, a_{l}\right) .
\end{aligned}
$$

Definition 5. For any two 2-tuples, $A:\left(s_{k}, a_{k}\right)$ and $B:\left(s_{l}, a_{l}\right)$, the distance between $A$ and $B$ is defined as follows:

$$
D(A, B)=\frac{\left|\left(k+a_{k}\right)-\left(l+a_{l}\right)\right|}{2} .
$$

Based on the definition of distance given by Eq. (1), the definition of the deviation degree between two 2-tuple sequences is given as follows. 
Definition 6. Let $f_{k}$ and $f_{l}$ be two 2-tuple sequences, where:

$$
\begin{aligned}
f_{k} & =\left(f_{k}(1), f_{k}(2), \cdots, f_{k}(n)\right) \\
& \left.=\left(s_{k 1}, a_{k 1}\right),\left(s_{k 2}, a_{k 2}\right), \cdots,\left(s_{k n}, a_{k n}\right)\right) \\
f_{l} & =\left(f_{l}(1), f_{l}(2), \cdots, f_{l}(n)\right) \\
& \left.=\left(s_{l 1}, a_{l 1}\right),\left(s_{l 2}, a_{l 2}\right), \cdots,\left(s_{\ln }, a_{\ln }\right)\right)
\end{aligned}
$$

$w_{j}$ is the weight of the $j$ th 2 -tuple, $j=1,2, \cdots, n$; thus, we set:

$$
\begin{aligned}
\delta\left(f_{k}, f_{l}\right)= & w_{1} D\left(f_{k}(1), f_{l}(1)\right)+w_{2} D\left(f_{k}(2), f_{l}(2)\right) \\
& +\cdots+w_{n} D\left(f_{k}(n), f_{l}(n)\right),
\end{aligned}
$$

where:

$$
D\left(f_{k}(j), f_{l}(j)=\frac{\left|\left(k j+a_{k j}\right)-\left(l j+a_{l j}\right)\right|}{2} .\right.
$$

Then, $\delta\left(f_{k}, f_{l}\right)$ is called a 2-tuple deviation degree between 2-tuple sequences, $f_{k}$ and $f_{l}$.

\subsection{A ranking method based on the 2-tuple deviation degree}

In this section, a ranking method based on a 2-tuple deviation degree is presented to evaluate and rank all alternative electric coal suppliers. Now, the detailed decision steps are given.

Step 1. For cost type attributes of $A_{1}$ price and $A_{3}$ delivery time, the following Eq. (2) is used to normalize their attribute values. For the benefit-type attribute $A_{2}$ quantity, the following Eq. (3) is used to normalize its attribute value. Then, the original decision-making matrix, $X=\left(x_{i j}\right)_{m \times 11}$, becomes a new decision-making matrix, $Y=\left(y_{i j}\right)_{m \times 11}$.

$$
\begin{aligned}
& y_{i j}=\frac{\max _{i} x_{i j}}{x_{i j}}, \quad i=1,2, \cdots, m, \quad j=1,3, \\
& y_{i j}=\frac{x_{i j}}{\max _{i} x_{i j}}, \quad i=1,2, \cdots, m, \quad j=2 .
\end{aligned}
$$

Step 2. For the attributes $A_{4}, A_{5}, \cdots, A_{11}$, their attributes such as best, good, acceptable, poor, and worst form a linguistic term set, $S=\left\{s_{0}, s_{1}, \cdots, s_{4}\right\}$, where:

$$
\begin{array}{ll}
s_{0}=\text { worst }, & s_{1}=\text { poor }, \quad s_{2}=\text { acceptable }, \\
s_{3}=\text { good }, & s_{4}=\text { best } .
\end{array}
$$

Then, the method given by Definition 1 is used to transform all linguistic fuzzy variables in decisionmaking matrix, $Y=\left(y_{i j}\right)_{m \times 11}$, into the 2-tuples; the method given by Definitions 2 and 3 is used to transform all real numbers in decision-making matrix, $Y=\left(y_{i j}\right)_{m \times 11}$, into the 2-tuples; then, a new normative 2 -tuple matrix, $Z=\left[\left(s_{i j}, a_{i j}\right)\right]_{m \times 11}$, is found;

Step 3. Define the positive ideal solution and the negative ideal solution from the 2-tuple matrix, $Z=$ $\left[\left(s_{i j}, a_{i j}\right)\right]_{m \times 11}$. The positive ideal solution, $f^{+}$, and the negative ideal solution, $f^{-}$, are determined as follows:

$$
\begin{gathered}
f^{+}=\left(f^{+}(1), f^{+}(2), \cdots, f^{+}(11)\right)=\left(\max _{i}\left(s_{i 1}, a_{i 1}\right),\right. \\
\left.\max _{i}\left(s_{i 2}, a_{i 2}\right), \cdots, \max _{i}\left(s_{i 11}, a_{i 11}\right)\right) \\
f^{-}=\left(f^{-}(1), f^{-}(2), \cdots, f^{-}(11)\right)=\left(\min _{i}\left(s_{i 1}, a_{i 1}\right)\right. \\
\left.\min _{i}\left(s_{i 2}, a_{i 2}\right), \cdots, \min _{i}\left(s_{i 11}, a_{i 11}\right)\right)
\end{gathered}
$$

where the compared operation "max" and "min" of any two 2-tuples are given in Definition 4;

Step 4. Calculate the deviation degree between each alternative and positive ideal solution $f^{+}$and calculate the deviation degree between each alternative and negative ideal solution $f^{-}$. The alternative $i$ is formed by 11 elements of each row in 2-tuple matrix $Z=\left[\left(s_{i j}, a_{i j}\right)\right]_{m \times 11}$, i.e.:

$$
\begin{aligned}
f_{i} & =\left(f_{i}(1), f_{i}(2), \cdots, f_{i}(11)\right) \\
& =\left(\left(s_{i 1}, a_{i 1}\right),\left(s_{i 2}, a_{i 2}\right), \cdots,\left(s_{i 11}, a_{i 11}\right)\right) \\
& i=1,2, \cdots, m,
\end{aligned}
$$

and the calculation formulas of deviation degree are presented as follows:

$$
\begin{aligned}
\delta\left(f^{+}, f_{i}\right)= & w_{1} D\left(f^{+}(1), f_{i}(1)\right)+w_{2} D\left(f^{+}(2), f_{i}(2)\right) \\
& +\cdots+w_{11} D\left(f^{+}(11), f_{i}(11)\right) \\
\delta\left(f^{-}, f_{i}\right)= & w_{1} D\left(f^{-}(1), f_{i}(1)\right)+w_{2} D\left(f^{-}(2), f_{i}(2)\right) \\
& +\cdots+w_{11} D\left(f^{-}(11), f_{i}(11)\right)
\end{aligned}
$$

where $w_{j}$ is the weight of the $j$ th attribute, $j=$ $1,2, \cdots, 11, D\left(f^{+}(j), f_{i}(j)\right)$ is the distance between $f^{+}(j)$ and $f_{i}(j)$, and $D\left(f^{-}(j), f_{i}(j)\right)$ is the distance between $f^{-}(j)$ and $f_{i}(j)$ (see Definition 5 ). The smaller the value of $\delta\left(f^{+}, f_{i}\right)$, the better the alternative $i$; the greater the value of $\delta\left(f^{-}, f_{i}\right)$, the better the alternative $i$

Step 5. Calculate the relative closeness degree for each alternative and positive ideal solution, $f^{+}$. The 
calculation formulas of relative closeness degree are as follows:

$$
r_{i}=\frac{\delta\left(f^{-}, f_{i}\right)}{\delta\left(f^{+}, f_{i}\right)+\delta\left(f^{-}, f_{i}\right)}, \quad i=1,2, \cdots, m
$$

Step 6. Rank all the alternative electric coal suppliers in accordance with the value of relative closeness degree, $r_{i}, i=1,2, \cdots, m$. The greater the value of $r_{i}$, the better the alter-native supplier $i$;

Step 7. Determine the final winners.

Suppose that the ranking order of the value of relative closeness degree $r_{i}$ is $r_{1} \geq r_{2} \geq \cdots \geq r_{m}$, and the corresponding maximum supply quantities of the suppliers to the buyer are $x_{12}, x_{22}, \cdots, x_{m 2}$. The rule of determining the final winners is that the buyer gives priority to allocating the electric coal to the supplier with a greater value of $r_{i}$. Firstly, the buyer will allocate the total amount, $Q_{0}$, of electric coal to the supplier with the greatest $r_{1}$, and Supplier 1 obtains the allowed supply quantity $q_{1}^{*}=x_{12}$. Secondly, the buyer will allocate the remaining amount $Q_{0}-x_{12}$ to the supplier with the second greatest $r_{2}$. If the condition $x_{22} \geq Q_{0}-x_{12}$ is satisfied, then Supplier 2 gets the allowed supply quantity $q_{2}^{*}=Q_{0}-x_{12}$ and $q_{3}^{*}=q_{4}^{*}=\cdots=q_{m}^{*}=0$, meaning that the allocation is over, and the suppliers with the value of $r_{i}$ in the top 2 are the winners. If $x_{22}<Q_{0}-x_{12}$, then $q_{2}^{*}=x_{22}$, and the residual amount, $Q_{0}-x_{12}-x_{22}$, will be allocated to the rest of suppliers sequentially by the similar method. Repeat the similar process until the total amount, $Q_{0}$, is fully allocated.

\section{A decision-making example of supplier selection in electric coal procurement}

In this section, a decision-making example of supplier selection in electric coal procurement is presented to show how to implement our optimal decision-making method for selecting green suppliers and to demonstrate the effectiveness of this method.
It is supposed that a buyer wants to procure 1100 tons of electric coal. Five risk neutral suppliers are allowed to participate in the supply competition, i.e., $M=\{1,2, \cdots, 5\}$. The buyer will measure and evaluate all electric coal suppliers' performance and select optimal suppliers from economic and environmental dimensions. The detailed evaluation attributes are given in Section 2, i.e., $A_{1}$ price (Yuan/ton), $A_{2}$ quantity (tons), $A_{3}$ delivery time (days), $A_{4}$ quality, $A_{5}$ supplier's reputation, $A_{6}$ carbon dioxide emission level, $A_{7}$ wastewater discharge level, $A_{8}$ solid waste generation level, $A_{9}$ recycling utilization rate of waste material, $A_{10}$ investment rate of environmental protection, and $A_{11}$ environmental management level. Let the weight set of the 11 attributes be $W=\left(w_{1}, w_{2}, \cdots, w_{11}\right)=$ $(0.15,0.05,0.15,0.15,0.1,0.1,0.05,0.05,0.05,0.1,0.05)$.

After evaluating 11 attributes for all 5 alternative electric coal suppliers, it is supposed that the buyer gives the original decision-making matrix, $X=$ $\left(x_{j i}\right)_{11 \times 5}, i=1,2, \cdots, 5, j=1,2, \cdots, 11$. All data are listed in Table 1.

In Table $1, s_{0}=$ worst, $s_{1}=$ poor, $s_{2}=$ acceptable, $s_{3}=$ good, and $s_{4}=$ best. The detailed decision process is as follows:

1. Use Eqs. (1), (2), and (3) to process the values of attributes $A_{1}, A_{2}$, and $A_{3}$ in matrix $X=\left(x_{j i}\right)_{11 \times 5}$; then, we obtain the normalized decision-making matrix, $Y=\left(y_{j i}\right)_{11 \times 5}$, as follows:

$$
Y=\left(\begin{array}{ccccc}
1.272 & 1.077 & 1.120 & 1 & 1.167 \\
0.833 & 0.729 & 0.625 & 0.833 & 1 \\
1.25 & 1.136 & 1 & 1.389 & 1.250 \\
s_{3} & s_{3} & s_{4} & s_{3} & s_{4} \\
s_{4} & s_{2} & s_{3} & s_{4} & s_{4} \\
s_{3} & s_{4} & s_{2} & s_{2} & s_{3} \\
s_{3} & s_{3} & s_{2} & s_{2} & s_{4} \\
s_{3} & s_{2} & s_{3} & s_{3} & s_{4} \\
s_{4} & s_{2} & s_{4} & s_{3} & s_{3} \\
s_{4} & s_{3} & s_{4} & s_{2} & s_{4} \\
s_{3} & s_{2} & s_{3} & s_{3} & s_{4}
\end{array}\right)
$$

Table 1. Original decision-making matrix.

\begin{tabular}{cccccc}
\hline Attribute & Supplier 1 & Supplier 2 & Supplier 3 & Supplier 4 & Supplier 5 \\
\hline$A_{1}$ & 220 & 260 & 250 & 280 & 240 \\
$A_{2}$ & 400 & 350 & 300 & 400 & 480 \\
$A_{3}$ & 20 & 22 & 25 & 18 & 20 \\
$A_{4}$ & $s_{3}$ & $s_{3}$ & $s_{4}$ & $s_{3}$ & $s_{4}$ \\
$A_{5}$ & $s_{4}$ & $s_{2}$ & $s_{3}$ & $s_{4}$ & $s_{4}$ \\
$A_{6}$ & $s_{3}$ & $s_{4}$ & $s_{2}$ & $s_{2}$ & $s_{3}$ \\
$A_{7}$ & $s_{3}$ & $s_{3}$ & $s_{2}$ & $s_{2}$ & $s_{4}$ \\
$A_{8}$ & $s_{3}$ & $s_{2}$ & $s_{3}$ & $s_{3}$ & $s_{4}$ \\
$A_{9}$ & $s_{4}$ & $s_{2}$ & $s_{4}$ & $s_{3}$ & $s_{3}$ \\
$A_{10}$ & $s_{4}$ & $s_{3}$ & $s_{4}$ & $s_{2}$ & $s_{4}$ \\
$A_{11}$ & $s_{3}$ & $s_{2}$ & $s_{3}$ & $s_{3}$ & $s_{4}$ \\
\hline
\end{tabular}




$$
R=\left(\begin{array}{ccccc}
\left(s_{1}, 0.272\right) & \left(s_{1}, 0.077\right) & \left(s_{1}, 0.120\right) & \left(s_{1}, 0\right) & \left(s_{1}, 0.167\right) \\
\left(s_{3}, 0.332\right) & \left(s_{3},-0.084\right) & \left(s_{3},-0.5\right) & \left(s_{3}, 0.332\right) & \left(s_{4}, 0\right) \\
\left(s_{1}, 0.25\right) & \left(s_{1}, 0.136\right) & \left(s_{1}, 0\right) & \left(s_{1}, 0.389\right) & \left(s_{1}, 0.250\right) \\
\left(s_{3}, 0\right) & \left(s_{3}, 0\right) & \left(s_{4}, 0\right) & \left(s_{3}, 0\right) & \left(s_{4}, 0\right) \\
\left(s_{4}, 0\right) & \left(s_{2}, 0\right) & \left(s_{3}, 0\right) & \left(s_{4}, 0\right) & \left(s_{4}, 0\right) \\
\left(s_{3}, 0\right) & \left(s_{4}, 0\right) & \left(s_{2}, 0\right) & \left(s_{2}, 0\right) & \left(s_{3}, 0\right) \\
\left(s_{3}, 0\right) & \left(s_{3}, 0\right) & \left(s_{2}, 0\right) & \left(s_{2}, 0\right) & \left(s_{4}, 0\right) \\
\left(s_{3}, 0\right) & \left(s_{2}, 0\right) & \left(s_{3}, 0\right) & \left(s_{3}, 0\right) & \left(s_{4}, 0\right) \\
\left(s_{4}, 0\right) & \left(s_{2}, 0\right) & \left(s_{4}, 0\right) & \left(s_{3}, 0\right) & \left(s_{3}, 0\right) \\
\left(s_{4}, 0\right) & \left(s_{3}, 0\right) & \left(s_{4}, 0\right) & \left(s_{2}, 0\right) & \left(s_{4}, 0\right) \\
\left(s_{3}, 0\right) & \left(s_{2}, 0\right) & \left(s_{3}, 0\right) & \left(s_{3}, 0\right) & \left(s_{4}, 0\right)
\end{array}\right)
$$

Box I

2. Use the transformation methods in Definition 1 , Definition 2, and Definition 3 to transform all attribute values in $Y=\left(y_{j i}\right)_{11 \times 5}$ into 2-tuples; then, the normative 2-tuple matrix $R=\left[\left(s_{j i}, a_{j i}\right)\right]_{11 \times 5}$ is obtained as shown in Box I.

3. Use Eqs. (4), (5), and (6) to determine compared sequences, $f_{1}, f_{2}, \cdots, f_{5}$, the positive ideal solution, $f^{+}$, and the negative ideal solution, $f^{-}$, in the normative 2 -tuple matrix, $R=\left[\left(s_{j i}, a_{j i}\right)\right]_{11 \times 5}$ :

$$
\begin{aligned}
f_{1}= & \left(s_{1}, 0.272\right),\left(s_{3}, 0.332\right),\left(s_{1}, 0.25\right),\left(s_{3}, 0\right), \\
& \left(s_{4}, 0\right),\left(s_{3}, 0\right),\left(s_{3}, 0\right),\left(s_{3}, 0\right), \\
& \left.\left(s_{4}, 0\right),\left(s_{4}, 0\right),\left(s_{3}, 0\right)\right), \\
f_{2}= & \left(s_{1}, 0.077\right),\left(s_{3},-0.084\right),\left(s_{1}, 0.136\right), \\
& \left(s_{3}, 0\right),\left(s_{2}, 0\right),\left(s_{4}, 0\right),\left(s_{3}, 0\right),\left(s_{2}, 0\right), \\
& \left.\left(s_{2}, 0\right),\left(s_{3}, 0\right),\left(s_{2}, 0\right)\right), \\
f_{3}= & \left(\left(s_{1}, 0.120\right),\left(s_{3},-0.5\right),\left(s_{1}, 0\right),\left(s_{4}, 0\right),\right. \\
& \left(s_{3}, 0\right),\left(s_{2}, 0\right),\left(s_{2}, 0\right),\left(s_{3}, 0\right),\left(s_{4}, 0\right), \\
& \left.\left(s_{4}, 0\right),\left(s_{3}, 0\right)\right), \\
f_{4}= & \left(\left(s_{1}, 0\right),\left(s_{3}, 0.332\right),\left(s_{1}, 0.389\right),\left(s_{3}, 0\right),\right. \\
& \left(s_{4}, 0\right),\left(s_{2}, 0\right),\left(s_{2}, 0\right),\left(s_{3}, 0\right),\left(s_{3}, 0\right), \\
f_{5}= & \left(\left(s_{1}, 0.167\right),\left(s_{4}, 0\right),\left(s_{1}, 0.25\right),\left(s_{4}, 0\right),\left(s_{4}, 0\right)\right), \\
& \left(s_{4}, 0\right),\left(s_{3}, 0\right),\left(s_{4}, 0\right),\left(s_{4}, 0\right),\left(s_{3}, 0\right), \\
&
\end{aligned}
$$

$$
\begin{aligned}
f^{+}= & \left(s_{1}, 0.272\right),\left(s_{4}, 0\right),\left(s_{1}, 0.389\right),\left(s_{4}, 0\right), \\
& \left(s_{4}, 0\right),\left(s_{4}, 0\right),\left(s_{4}, 0\right),\left(s_{4}, 0\right),\left(s_{4}, 0\right), \\
& \left.\left(s_{4}, 0\right),\left(s_{4}, 0\right)\right), \\
f^{-}= & \left(\left(s_{1}, 0\right),\left(s_{3},-0.5\right),\left(s_{1}, 0\right),\left(s_{3}, 0\right),\left(s_{2}, 0\right),\right. \\
& \left(s_{2}, 0\right),\left(s_{2}, 0\right),\left(s_{2}, 0\right),\left(s_{2}, 0\right),\left(s_{2}, 0\right), \\
& \left(s_{2}, 0\right) .
\end{aligned}
$$

4. Use Eqs. (7) and (8) to calculate the deviation degrees $\delta\left(f^{+}, f_{i}\right)$ and $\delta\left(f^{-}, f_{i}\right)$, and the results are as follows:

$$
\begin{array}{ll}
\delta\left(f^{+}, f_{1}\right)=0.227, & \delta\left(f^{+}, f_{2}\right)=0.458, \\
\delta\left(f^{+}, f_{3}\right)=0.328, & \delta\left(f^{+}, f_{4}\right)=0.437, \\
\delta\left(f^{+}, f_{5}\right)=0.093, & \delta\left(f^{-}, f_{1}\right)=0.435, \\
\delta\left(f^{-}, f_{2}\right)=0.204, & \delta\left(f^{-}, f_{3}\right)=0.334, \\
\delta\left(f^{-}, f_{4}\right)=0.225, & \delta\left(f^{-}, f_{5}\right)=0.569 .
\end{array}
$$

5. Use Eqs. (9) to calculate the relative closeness degree $r_{i}, i=1,2, \cdots, 5$.

$$
\begin{array}{ll}
r_{1}=0.657, & r_{2}=0.309, \quad r_{3}=0.504, \\
r_{4}=0.340, & r_{5}=0.859 .
\end{array}
$$

6. Rank all 5 alternative electric coal suppliers in accordance with $r_{i}, i=1,2, \cdots, 5$. Since:

$$
r_{5}>r_{1}>r_{3}>r_{4}>r_{2}
$$

the five alternative suppliers are ranked as Supplier $5 \succ$ Supplier $1 \succ$ Supplier $3 \succ$ Supplier $4 \succ$ Supplier 2 . 
7. Use the method for determining winners given in Section 3.2 to determine the final winners.

First, the buyer allocates the total amount $Q_{0}=$ 1100 tons of electric coal to Supplier 5 with the greatest relative closeness degree, $r_{5}$, and Supplier 5 gets the allowable supply quantity, $q_{5}^{*}=x_{25}=480$ tons. Second, the buyer allocates the remaining amount of $Q_{0}-q_{5}^{*}=$ $1100-480=620$ tons to Supplier 1 . Since the maximum supply quantity of Supplier 1 is $x_{21}=400$ tons and $x_{21}=400<620$, Supplier 1 gets the allowable supply quantity of $q_{1}^{*}=400$ tons. Third, the buyer allocates the remaining amount of $Q_{0}-q_{5}^{*}-q_{1}^{*}=1100-480-400$ tons to Supplier 3. Since $c_{23}=300>220$, Supplier 3 can only get the allowable supply quantity of 220 tons. Now, the allocation is over, and Supplier 5, Supplier 1, and Supplier 3 are the final three winners.

In the final contract, Supplier 5 will supply 480 tons of goods to the buyer at a transaction price of 240 Yuan/ton. Supplier 1 will supply 400 tons of goods at 220 Yuan/ton. Supplier 3 will supply 220 tons goods at 250 Yuan/ton.

\section{Conclusion}

This study focused on the problem of selecting green supplies in the multi-attribute and multi-source procurement of electric coal. Then, it presented a new index system of supplier selection by considering both the economic and environmental factors. This new evaluation system effectively improved the traditional evaluation system, which only considered economic factors such as price, quality, delivery time, flexibility, and so on. We also considered the green supplier selection under fuzzy information environment and presented a multi-attribute decision-making method based on linguistic 2-tuple to rank all alternative suppliers. This method may well improve the procurement efficiency of electric coal and can effectively prevent the information loss in the decision-making process; in addition, it also provides a feasible winner selection method for a kind of hybrid multi-attribute decision-making problems with hybrid attribute data. In the future, we will further study the sustainable procurement decision of electric coal under a more complex information environment, e.g., the supplier selection with hybrid attribute data (precise values, interval numbers, and the linguistic fuzzy variable coexist).

\section{Acknowledgments}

This work is supported by the National Natural Science Foundation of China (No. 71671135, 61703317), the 2018 Soft Science Research Project of Technology Innovation in Hubei province (No. 2018ADC044), and the Fundamental Research Funds for the Central Universities (No. 2017 IVA 067).

\section{References}

1. Zhao, X.L. and Qi, J.X. "Regulation model of supply chain cooperative conflict-the case of coal and electric power enterprises", Chinese Journal of Management Science, 16(4), pp. 96-103 (2008).

2. Cattaneo, C., Manera, M., and Scarpa, E. "Industrial coal demand in China: A provincial analysis", Resource and Energy Economics, 33(1), pp. 12-35 (2011).

3. Rao, C.J., Zheng, J.J., Hu, Z., and Goh, M. "Compound mechanism design on multi-attribute and multisource procurement of electricity coal", Scientia Iranica, Transactions E: Industrial Engineering, 23(3), pp. 1384-1398 (2016).

4. Meade, N. and Islam, T. "Modelling European usage of renewable energy technologies for electricity generation", Technological Forecasting \& Social Change, 90, pp. 497-509 (2015).

5. Rao, C.J., Zhao, Y., and Li, C.F. "Asymmetric Nash equilibrium in emission rights auctions", Technological Forecasting and Social Change, 79(3), pp. 429-435 (2012).

6. Rao, C.J., Goh, M., Zhao, Y., and Zheng, J.J. "Location selection of sustainability city logistics centers", Transportation Research Part D: Transport and Environment, 36, pp. 29-44 (2015).

7. Yang, N., Liao, X.W., and Huang, W.W. "Decision support for preference elicitation in multi-attribute electronic procurement auctions through an agentbased intermediary", Decision Support Systems, 57, pp. 127-138 (2014).

8. Shiromaru, I., Inuiguchi, M., and Sakawa, M. "A fuzzy satisficing method for electric power plant coal purchase using genetic algorithm", European Journal of Operational Research, 126, pp. 218-230 (2000).

9. Lai, S.Y. and Yang, H.M. "Nash equilibrium analysis of electric power supply chain with fuel supplier", in Proceedings of Asia-Pacific Power and Energy Engineering Conference, pp. 582-590 (2009).

10. Dai, Y., Yang, H.M., and Wu, J. "Electricity supply chain coordination based on quantity discount contracts", in Proceedings of the IEEE International Conference on Industrial Technology, pp. 383-393 (2009).

11. Yan, G. "Study on procurement coordination of supply chain in internet-based E-business environment", Master Thesis of Xiamen University, Xiamen (2008).

12. Rao, C.J., Xiao, X.P., Goh, M., Zheng, J.J., and Wen, J.H. "Compound mechanism design of supplier selection based on multi-attribute auction and risk management of supply chain", Computers \& Industrial Engineering, 105, pp. 63-75 (2017).

13. Rao, C.J., Goh, M., and Zheng, J.J. "Decision mechanism for supplier selection under sustainability", International Journal of Information Technology \& Decision Making, 16(1), pp. 87-115 (2017).

14. Rao, C.J., Xiao, X.P., Xie, M., Goh, M., and Zheng, J.J. "Low carbon supplier selection under multi-source 
and multi-attribute procurement", Journal of Intelligent \& Fuzzy Systems, 32(6), pp. 4009-4022 (2017).

15. Rao, C.J. and Peng, J. "Fuzzy group decision making model based on credibility theory and gray relative degree", International Journal of Information Technology \& Decision Making, 8, pp. 515-527 (2009).

16. Sun, B.Z., Ma, W.M., and Qian, Y.H. "Multigranulation fuzzy rough set over two universes and its application to decision making", Knowledge-Based Systems, 123, pp. 61-74 (2017).

17. Liu, S., Chan, F.T.S., and Ran, W.X. "Multi-attribute group decision-making with multi-granularity linguistic assessment information: An improved approach based on deviation and TOPSIS", Applied Mathematical Modelling, 37, pp. 10129-10140 (2013).

18. Sun, B.Z., Ma, W.M., and Xiao, X. "Three-way group decision making based on multigranulation fuzzy decision-theoretic rough set over two universes", International Journal of Approximate Reasoning, 81, pp. 87-102 (2017).

19. Wan, S.P., Wang, Q.Y., and Dong, J.Y. "The extended VIKOR method for multi-attribute group decision making with triangular intuitionistic fuzzy numbers", Knowledge-Based Systems, 52, pp. 65-77 (2013).

20. Xu, Z.S. "A method based on distance measure for interval-valued intuitionistic fuzzy group decision making", Information Sciences, 180, pp. 181-190 (2010).

21. Rao, C.J., Zheng, J.J., Wang, C., and Xiao, X.P. "A hybrid multi-attribute group decision making method based on grey linguistic 2-tuple", Iranian Journal of Fuzzy Systems, 13(2), pp. 37-59 (2016).

22. Peng, B., Zhou, J.M., and Peng, D.H. "Cloud 2model based approach to group decision making with uncertain pure linguistic information", Journal of Intelligent \& Fuzzy Systems, 32(3), pp. 1959-1968 (2017).

23. Sun, B.Z., Ma, W.M., and Li, X.N. "Linguistic value soft set-based approach to multiple criteria group decision-making", Applied Soft Computing, 58, pp. 285-296 (2017).

24. Wan, S.P., Xu, G.L., and Dong, J.Y. "Supplier selection using ANP and ELECTRE II in interval 2-tuple linguistic environment", Information Sciences, 385386, pp. 19-38 (2017).

25. Geng, X.L., Qiu, H.Q., and Gong, X.M. "An extended 2-tuple linguistic DEA for solving MAGDM problems considering the influence relationships among attributes", Computers \& Industrial Engineering, 112, pp. 135-146 (2017).

26. Sun, B.Z., Ma, W.M., and Zhao, H.Y. "An approach to emergency decision-making based on decision-theoretic rough set over two universes", Soft Computing, 20(9), pp. 3617-3628 (2016).

27. Zhu, H., Zhao, J.B., and Xu, Y. "2-dimension linguistic computational model with 2-tuples for multi-attribute group decision making", Knowledge-Based Systems, 103, pp. 132-142 (2016).
28. Wu, Y.N., Chen, K.F., Zeng, B.X., Yang, M., and Zhang, H.B. "A cloud decision framework in pure 2tuple linguistic setting and its application for lowspeed wind farm site selection", Journal of Cleaner Production, 142, pp. 2154-2165 (2017).

29. Liu, P.D., Tang, G.L., Liu, W.L., Mohammadi, Z., and Salarieh, H. "Induced generalized interval neutrosophic Shapley hybrid operators and their application in multi-attribute decision making", Scientia Iranica, Transactions E: Industrial Engineering, 24(4), pp. 2164-2181 (2017).

30. Yue, Z. and Jia, Y. "A projection-based approach to intuitionistic fuzzy group decision making", Scientia Iranica, Transactions E: Industrial Engineering, 24(3), pp. 1505-1518 (2017).

31. Wan, S.P. and Xu, J. "A method for multi-attribute group decision making with triangular intuitionistic fuzzy numbers and application to trustworthy service selection", Scientia Iranica, Transactions E: Industrial Engineering, 24(2), pp. 794-807 (2017).

32. Wang, W.Z. and Liu, X.W. "The multi-attribute decision making method based on interval-valued intuitionistic fuzzy Einstein hybrid weighted geometric operator", Computers and Mathematics with Applications, 66, pp. 1845-1856 (2013).

33. Wei, G.W. "Grey relational analysis method for 2tuple linguistic multiple attribute group decision making with incomplete weight information", Expert Systems with Applications, 38, pp. 4824-4828 (2011).

34. Zhou, L.G. and Chen, H.Y. "The induced linguistic continuous ordered weighted geometric operator and its application to group decision making", Computers \& Industrial Engineering, 66, pp. 222-232 (2013).

35. Liu, P.D. and Wang, Y.M. "Multiple attribute group decision making methods based on intuitionistic linguistic power generalized aggregation operators", Applied Soft Computing, 17, pp. 90-104 (2014).

36. Li, D.F. and Liu, J.C. "A parameterized non-linear programming approach to solve matrix games with payoffs of I-fuzzy numbers", IEEE Transactions on Fuzzy Systems, 23(4), pp. 885-896 (2015).

37. Ji, Y. and Goh, M. "Proximal point algorithms for multi-criteria DC programming with applications to Portfolio optimization", Journal of Optimization Theory and Applications, 169(1), pp. 280-289 (2016).

38. Yu, D.J. and Li, D.F. "Managing interval-valued multiplicative hesitant fuzzy information in GDM problems", Scientia Iranica, Transactions E: Industrial Engineering, 23(4), pp. 1918-1927 (2016).

39. Rao, C.J., Zhao, Y., Zheng, J.J. Wang, C., and Chen, Z.W. "An extended uniform price auction mechanism of homogeneous divisible goods: supply optimization and non-strategic bidding", International Journal of Production Research, 54(13), pp. 4028-4042 (2016).

40. Chen, L., Peng, J., Liu, Z., and Zhao, R. "Pricing and effort decisions for a supply chain with uncertain information", International Journal of Production Research, 55(1), pp. 264-284 (2017). 
41. Liu, Z., Zhao, R., Liu, X., and Chen, L. "Contract designing for a supply chain with uncertain information based on confidence level", Applied Soft Computing, 56, pp. 617-631 (2017).

42. Li, Z., Chen, L., and Nan, G. "Small-scale renewable energy source trading: A contract theory approach", IEEE Transactions on Industrial Informatics, 14(4), pp. 1491-1500 (2018).

43. Rao, C.J., Zhao, Y., and Ma, S.H. "Procurement decision making mechanism of divisible goods based on multi-attribute auction", Electronic Commerce Research and Applications, 11, pp. 397-406 (2012).

44. Rao, C.J., Xiao, X.P., and Peng, J. "Novel combinatorial algorithm for the problems of fuzzy grey multi-attribute group decision making", Journal of Systems Engineering and Electronics, 18(4), pp. 774780 (2007).

45. Qu, S.J., Goh, M., Ji, Y., and Rober, D.S. "A new algorithm for linearly constrained C-convex vector optimization with a supply chain network risk application", European Journal of Operational Research, 247, pp. 359-365 (2015).

46. Rao, C.J. and Li, P. "Multi-stage sequential uniform price auction mechanism for divisible goods", Expert Systems with Applications, 40(15), pp. 6105-6114 (2013).

47. Herrera, F. and Martinez, L. "A 2-tuple fuzzy linguistic representation model for computing with words", IEEE Trans on Fuzzy Systems, 8, pp. 746-752 (2000).

48. Herrera, F. "A model based on linguistic 2-tuple for dealing with multi-granularity hierarchical linguistic contexts in multi-expert decision-making", IEEE Trans on System Man and Cybernetics, Part B: Cybernetics, 31, pp. 227-234 (2001).

49. Zhang, H.M. "Some interval-valued 2-tuple linguistic aggregation operators and application in multiattribute group decision making", Applied Mathematical Modelling, 37, pp. 4269-4282 (2013).

50. Chen, Y.F., Technical Condition of Coal Used for Pulverized Coal-fired Boiler for Power Generation (GB/T7562-2010), China Standards Press, Beijing (2010).

\section{Biographies}

Congjun Rao was born in Huanggang, China in 1979. He received MS degree from Wuhan University of Technology, China in 2006 and received his $\mathrm{PhD}$ degree from Huazhong University of Science and Tech-nology, China in 2011. His research interests include supply chain management, auction theory, and decision theory and method.

Cheng Wang received MS degree from Wuhan University of Technology, China in 2006 and his PhD degree is from Huazhong University of Science and Technology. He has worked as a postdoctoral fellow in the School of Mathematics and Statistics at Huazhong University of Science and Technology from 2012 to 2016. She is currently an Associate Professor in Hubei University of Education. His research interests include system optimization and control and decision theory.

Zhuo Hu received $\mathrm{PhD}$ degree from Huazhong University of Science and Technology, China and was a visiting academic at Imperial College London for a year. He is now a Lecturer of the School of Automation at Wuhan University of Technology. His current research interests include decision theory and method, decision support system, product conceptual design, auction theory, and computer vision.

Ying Meng received BS degree from Shanxi University, China in 2017. She is currently a Master Degree candidate at the Wuhan University of Technology. Her research interests include statistical forecasting and decision-making as well as decision theory and methods.

Ming Liu received BS degree from Hubei University of Education, China in 2017. She is currently a master degree candidate in the Wuhan University of Technology. Her research interests include statistical forecasting and decision-making as well as decision theory and methods. 